\title{
Stress Utilization of Jacket Structure Under Environmental Loading
}

\author{
Iberahin Jusoh \\ Mechanical Engineering Department, \\ College of Engineering and Islamic Architecture \\ Umm Al-Qura Univerrsity, Makkah, Saudi Arabia.
}

\begin{abstract}
This paper describes a procedure to identify the critical members in an offshore jacket structure in Malaysia waters by adopting the probabilistic approach. The hydrodynamic design loads on the jacket structure are imposed by considering the joint probability occurrence of the met-ocean phenomena (significant wave height and spectral peak period). This forms the basic calculation of the long-term response from which the extreme response can be estimated. Stochastic dynamic response analyses are performed in the time domain by stepwise integration. Necessary simulation lengths are established. Interaction ratios of the members are computed based on the API RP2A-WSD design code to determine the level of stress utilization ratio of the jacket's members. The inclined structural member located at elevation $21.3 \mathrm{~m}$ from the sea bed is found to have the highest stress utilization ratio of 0.2884 . The results also confirm that the structure is strong by having a high reserve strength.
\end{abstract}

Keywords- Stress utilization ratio; jacket structure; probabilistic analysis; environmental loading.

\section{INTRODUCTION}

The probabilistic approach is widely used in the design and analysis of offshore structures. The application of this approach has gained wide acceptance not only in the studies of fluid loading but also in the structural analysis due to its ability to capture the randomness of nature. Traditionally, the deterministic method which is the design wave approach is the simplest way of analyzing the fluid loading on a structure and the most well-established design practice. In this approach, all the environmental loadings are assumed to act as unidirectional. However, in reality, all the extreme environmental parameters will rarely occur simultaneously and cause the worst structural effect. Extensive researches have been carried out on the effects of the joint probability of environmental loading on the structural response [1], [2], [3], [4]. The concept of joint probability has received increasing attention as the measured data set of the metocean has available and confidence in the hindcast model has grown. This approach is here employed for analysis fluid loading where the joint probability model for significant wave height and the spectral peak period is considered.

In structural analysis, the spectral approach in the frequency domain is often employed compared to the time domain. It is the preferred method as it is less time consuming compared to the time domain approach. However, the wave loads on complex ocean structures typically vary non-linearly with the wave elevation. Thus, time-domain simulation remains one of the few general techniques for estimating response statistics under random wave load. The stress analysis is performed in the time domain to identify the critical members.

\section{PROBABILISTIC ENVIRONMENTAL LOADING MODEL}

The procedures used for designing offshore structures for extreme conditions, the environmental loads are based on a deterministic, regular wave. This deterministic fluid loading model is highly simplified of an abstract in nature. Studies made by [5] showed that the deterministic fluid loading model predicts fluid loads about $10 \%$ lower than those predicted by the probabilistic model. Therefore, the probabilistic model would best describe a random condition in the ocean environment.

The total wave force is calculated based on the extreme conditions, which produces the largest environmental load on the jacket. The sea condition: $H_{s}=5.2 \mathrm{~m}, T_{p}=9.9 \mathrm{~s}, \gamma=3.3$ and the current profile as illustrated in Fig. 1.

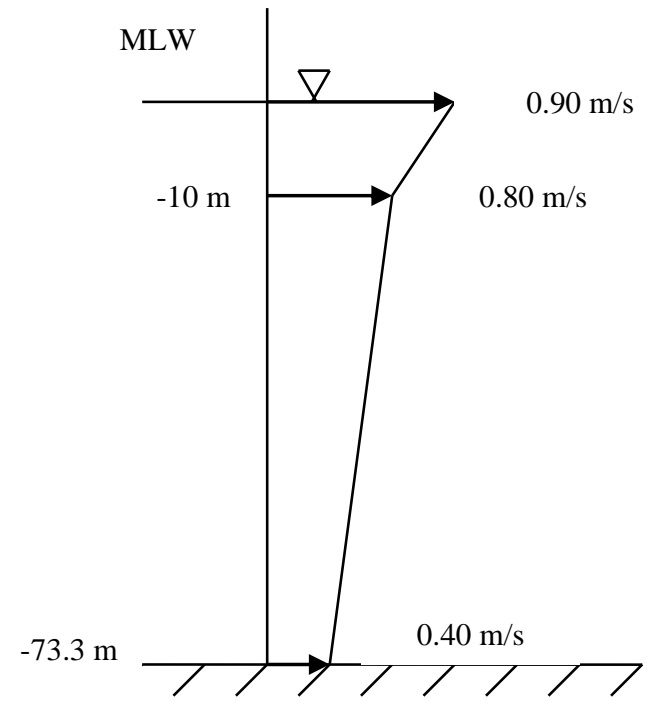

Fig. 1: Current profile for storm condition

A Gaussian wave elevation $\eta(t)$, is first simulated as

$$
\eta(t)=\sum_{k=1}^{n} a_{k} \cos \left(\omega_{k} t+\theta_{k}\right)
$$

The magnitude of the $a_{k}$ is related to the one-sided JONSWAP power spectrum of the waves $S_{\eta}\left(\omega_{k}\right)$ by

$$
a_{k}=\sqrt{2 S_{\eta}\left(\omega_{k}\right) \Delta \omega}
$$


where $\omega_{k}$ is the circular frequency of a particular harmonic component and $\theta_{k}$ is a random phase.

The applied force $f(x, c)$ per unit length, at elevation $\mathrm{z}$ and leg location, is calculated from the Morison equation:

$$
f(x, z)=\rho R_{D} C_{D}\left(u(x, z)+u_{o}\right)\left|u(x, z)+u_{o}\right|+\rho \pi R_{M}^{2} C_{M} \dot{u}(x, z)
$$

Absolute fluid velocity is used. The total forces are then found by integrating Morison's equation to the exact free surface. When this is above the mean water level, kinematics from linear wave theory is extended by constant stretching [6]. The Linear Airy Theory is used with empirical modification to take account of the constant stretching.

The current is assumed to be in the same direction as the wave loading. Adjustment to the current profile is made above the mean water level to take account of the wave and current interaction. The current profile is assumed to stretch above the mean wave line until it reaches the water surface as shown in Fig. 2. It is the most plausible since it approximately represents the convection of particles from crest to trough in the wave when that particle has its horizontal velocity increased by the presence of the current [7].

The force exerted by wind is assumed static. Wind loading is fixed at the highest elevation of the jacket structure at the incidence direction of 0 -degree for the simulation of 0 degree to 45-degree. The input of the environmental parameters for the structural analysis is summarised in Table 1.

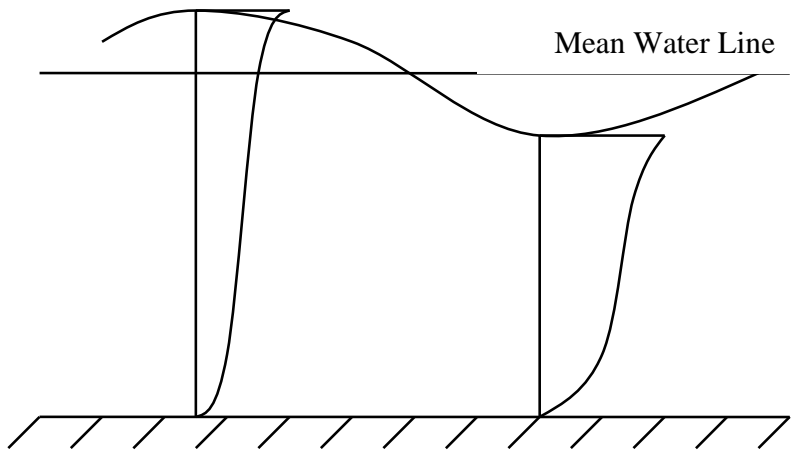

Fig. 2: Current Profile Stretching, the profile is stretched or compressed vertically but the current velocity at any proportion of the instantaneous depth $d+\eta$ is constant.

TABLE 1: Input Parameters for Environmental Loading

\begin{tabular}{|c|c|}
\hline Parameter & Value \\
\hline Significant Wave Height & $5.2 \mathrm{~m}$ \\
\hline Associated Wave Period & $9.9 \mathrm{~s}$ \\
\hline Wave Spectrum & Jonswap \\
\hline$C_{D}$ & 0.7 \\
\hline$C_{M}$ & 2.0 \\
\hline Wind Speed (Gust) & $26.44 \mathrm{~m} / \mathrm{s}$ \\
\hline Current Profile & $\begin{array}{c}\text { Bilinear } \\
\text { Mudline }-40 \mathrm{~cm} / \mathrm{s} \\
\text { MWL- } 90 \mathrm{~cm} / \mathrm{s}\end{array}$ \\
\hline
\end{tabular}

\section{NON LINEAR DYNAMIC ANALYSIS}

The long-term response sea state is specified by a model spectrum with significant wave height $\left(\mathrm{H}_{\mathrm{s}}\right)$ and spectral peak period $\left(T_{p}\right)$ as parameters. The relationship between the load and response stochastic process is given by the dynamic equilibrium equation on the incremental form:

$$
M \Delta \ddot{x}_{t}+C \Delta \dot{x}_{t}+K \Delta x_{t}=\Delta F_{t}
$$

where $M$ is a mass matrix, $C$ is a damping matrix, $K$ is a stiffness matrix, $\Delta F_{\mathrm{t}}$ is a vector of incremental hydrodynamic nodal point forces in-line with the wave direction, $\Delta \mathrm{x}_{\mathrm{t}}$ is an incremental structural displacement vector, $\Delta \dot{x}_{\mathrm{t}}$ is an incremental structural velocity vector and $\Delta \ddot{x}_{\mathrm{t}}$ is an incremental structural acceleration.

Sample time series of wave kinematics are simulated using independent random phases angles uniformly distributed between 0 and $2 \pi$. The hydrodynamic force vector at each discrete time step is determined from the Morison equation containing the velocity and acceleration of the water particles.

The response process samples are obtained by a step-wise numerical integration procedure. A Newmark- $\beta$ method with $\beta=0.25$ and $\gamma=0.5$ is employed, corresponding to the constant average acceleration algorithm. An iteration is required at each step as the force process depends on the response.

\section{STRUCTURAL MODEL}

The structure used in this study is a medium water depth jacket structure which is installed in the South China Sea at the water depth of $73.3 \mathrm{~m}$. It is a 4-legged jacket that has 5 elevations that consist of horizontal, vertical and inclined bracing as shown in Fig. 3 .

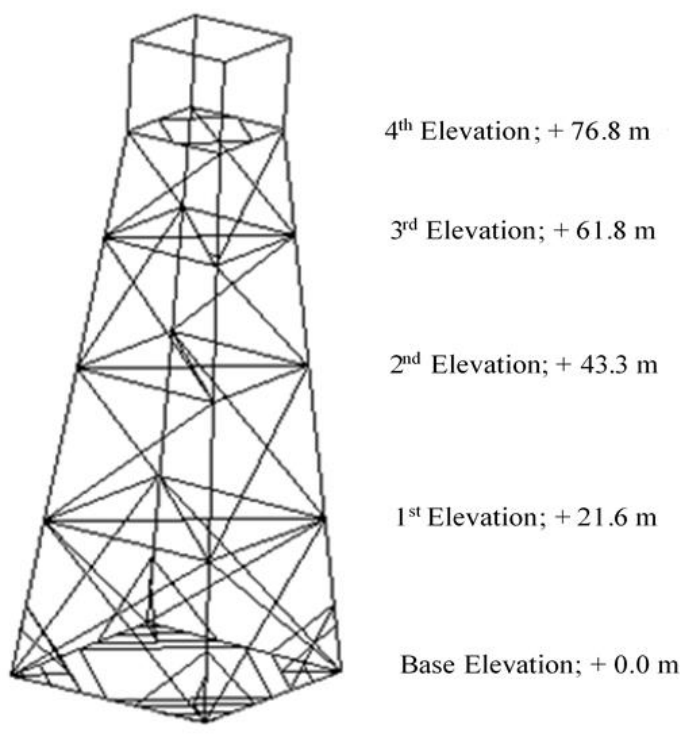

Fig. 3: Jacket Structure

The structure is made of steel tubular with the Modulus Young of $200 \mathrm{GN} / \mathrm{m}^{2}$ and a yield strength of $250 \mathrm{MPa}$. Each of the jacket legs is supported with a pile-driven through the foundation and sealed with grout. The four legs are battered to achieve better stability against toppling.

The jacket has four elevations. The base, which is position on the seabed, has a dimension of $29.41 \mathrm{~m} \times 29.41 \mathrm{~m}$ from the plan view. The first elevation is $21.8 \mathrm{~m}$ from the mudline. It has a dimension of $25.05 \mathrm{~m} \times 25.05 \mathrm{~m}$ from the top view. 
This elevation has the simplest structure as it only consists of horizontal X-bracing. The second and third elevations have the same structure which is the X-bracing and the T-bracing attached to one of its X-bracing. They are respectively $43.3 \mathrm{~m}$ and $61.8 \mathrm{~m}$ from the mudline with a dimension of $20.75 \mathrm{~m} \times$ $20.75 \mathrm{~m}$ and $17.05 \mathrm{~m} \times 17.05 \mathrm{~m}$ from the plan view. The top elevation which is the fourth elevation has the most complex structure as it consists mostly of T-bracing and K-bracing. It has a dimension of $14.05 \mathrm{~m} \times 14.05 \mathrm{~m}$ from the plan view at the elevation of $76.8 \mathrm{~m}$ from the mudline. The main jacket leg has the largest diameter, which is $1.1684 \mathrm{~m}$ and the wall thickness of $0.0127 \mathrm{~m}$.

The jacket structure is modeled by using the finite element simulation software. Simplifications of the structure are made to minimize modeling error and to reduce the simulation time but retaining its essential features. The jacket frame is modeled by using the immersed pipe option. The element has six degrees of freedom, 3 translations in the nodal axis, $x, y$ and $\mathrm{z}$ and 3 rotations about its nodal axis, $\mathrm{x}, \mathrm{y}, \mathrm{z}$. The load of the top deck is evenly distributed on the jacket leg.

\section{SIMULATION STUDY}

The results of the probabilistic analysis are presented in the time series form. Unlike the spectral method, where the results are generated in a spectral form with the root means square value, the probabilistic method does not have a particular method in establishing its results. The results generated in the time domain probabilistic method show a degree of variability and randomness. Thus, this variability and randomness directly suggest the simulation lengths [8].

From simulations studies [8], it has been revealed that there is a roughly quadratic relation between maximum wave elevation, $\eta_{\max }$ and maximum wave force $F_{\max }$. This suggests that $F_{\max }$ should show a greater scatter than $\eta_{\max }$ :

$$
V_{F \max } \approx 2 V_{\eta \max }
$$

A virtue of this estimate is that because $\eta(t)$ is Gaussian, analytical estimates of $\mathrm{V}_{\eta \max }$ are available [9];

$$
V_{\eta \max } \approx[0.45+1.56 \ln N]^{-1} ; \quad N={ }^{T}{ } / T_{z}
$$

In the present case study, $\mathrm{T}_{\mathrm{p}}=9.9 \mathrm{~s}$ and $\gamma=3.3$. Thus $\mathrm{T}_{\mathrm{z}}=$ 7.73 s. Hence $V_{\eta \max }=0.078$. and $V_{F \max }=0.156$. These values agree well with the observed value; $\mathrm{V}_{\eta_{\max }}=0.07$ and $\mathrm{V}_{\mathrm{Fmax}}=0.14,[5]$.

From here, simulation lengths can be established. For example, $95 \%$ confidence intervals are found by multiplying our best (mean) estimate by $(1 \pm 2 V / \sqrt{n})$. Thus, if it seeks (with $95 \%$ confidence) that the estimate lies within $10 \%$ on either side of the true value, we require $2 V / \sqrt{n}=0.1$ and hence;

$$
\eta_{\text {required }}=(20 \mathrm{~V})^{2}
$$

$\eta_{\text {required }}$ can apply to estimate the maximum wave elevation, force or response provided $\mathrm{V}$ reflects the relevant coefficient of variation $(\mathrm{CoV})$ value. Therefore, the number of simulations required for this study based on the maximum wave elevation generated is 7 sets of simulations with each set of 6 hours each. This makes the total of time which is needed to run a completed of simulation with the variance of $10 \%$ and error tolerance of $95 \%$ is 42 hours.

\section{RESULTS AND DISCUSSION}

The simulations are carried out in four-wave incidence directions; 0-degree, 15-degree, 30-degree and 45-degree. Due to the symmetrical features of the structure, the simulations are only performed up to 45 degree. The output generated from the simulations is axial stress for node $\mathrm{I}$ and $\mathrm{J}$, bending stress for node I and J, and nodal displacement. These stresses are due to external and transferred forces exerted onto the structure. The horizontal forces cause horizontal shear load on the structure is called base shear and it is influenced by the wave height. In this study, the magnitude of the base shear on the structure is shown in Fig. 4. It clearly illustrated that the base shear increases quadratically with the increase of wave height.

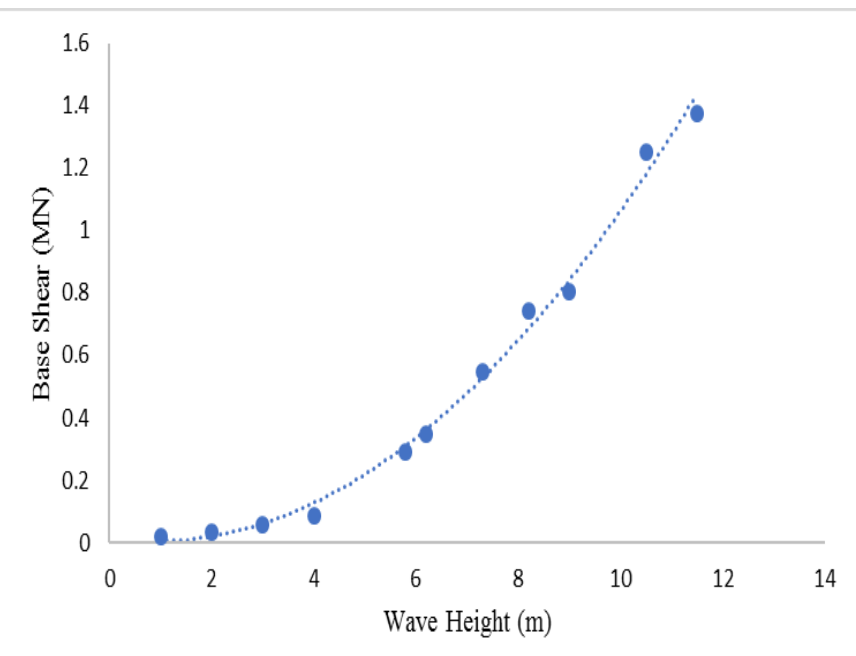

Fig. 4. Variation of base shear to wave height increment for wave direction, 0-degree

From the results of the simulation, the stress utilization ratio is calculated for every member for nodes I and J. The stress utilization ratio is a ratio to check the integrity of a member. If the ratio is low, then the reserve strength is high, it means that the structure is strong to withstand the loadings which are imposed on it and vice versa. Generally, if the ratio is less than one the structure is considered safe.

The definition of the stress utilization ratio which is used in this study is based on the criteria set by API Working Stress Design code [10]. Stress utilization ratio for a member under combined stress, combined axial compression/tension, and bending, can be defined as:

$$
\frac{f_{a}}{0.6 F y}+\frac{f_{b}}{F b} \leq 1.0
$$

where $f_{a}$ and $f_{b}$ are output generate by simulations, while $F_{y}$ and $F_{b}$ are allowable axial (tension or bending) stress and allowable bending stress.

The stress utilization ratios for critical members are tabulated in Table 2 to Table 5. In Table 2, the maxima value 
for stress utilization ratio under the condition of axial and bending stress for 0 -degree of wave direction is 0.2864 . This value decreases as the direction of the wave attack is increased from 0-degree to 45-degree. The stress utilization ratios are greater in the second and the base elevation. This is due to the force transfer by the members from the top to bottom. The base shear and overturning moment for the wave attack of 0-degree are $393.56 \mathrm{kN}$ and $127.89 \mathrm{kNm}$ respectively. Further reporting on critical member's stresses leading to structural failure may be found elsewhere [4].

From Tables 2 to 5 , the results of the analysis show that the most critical element on the structure is element number 70. This is true for all three wave-structure incidence directions. The maximum stress utilization ratio for this element occurred when the wave is from 0-degree direction and the lowest stress utilization ratio is when the wave from the 45-degree direction as illustrated in Fig. 5.

TABLE 2: Stress utilization ratio for 5 most critical members in the wave

\begin{tabular}{|c|c|c|c|c|}
\hline \multirow{2}{*}{ Rank } & \multicolumn{3}{|c|}{ Node I } & \multicolumn{2}{c|}{ Node J } \\
\cline { 2 - 5 } & Element & $\begin{array}{c}\text { Stress } \\
\text { Utilisation }\end{array}$ & Element & $\begin{array}{c}\text { Stress } \\
\text { Utilisation }\end{array}$ \\
\hline 1 & 70 & 0.29 & 70 & 0.28 \\
\hline 2 & 63 & 0.22 & 62 & 0.22 \\
\hline 3 & 61 & 0.22 & 64 & 0.22 \\
\hline 4 & 57 & 0.21 & 57 & 0.21 \\
\hline 5 & 71 & 0.20 & 88 & 0.20 \\
\hline
\end{tabular}

TABLE 3: Stress utilization ratio for 5 most critical members in the wave direction of 15 degree

\begin{tabular}{|c|c|c|c|c|}
\hline \multirow{2}{*}{ Rank } & \multicolumn{2}{|c|}{ Node I } & \multicolumn{2}{c|}{ Node J } \\
\cline { 2 - 5 } & Element & $\begin{array}{c}\text { Stress } \\
\text { Utilisation }\end{array}$ & Element & $\begin{array}{c}\text { Stress } \\
\text { Utilisation }\end{array}$ \\
\hline 1 & 70 & 0.29 & 70 & 0.28 \\
\hline 2 & 69 & 0.22 & 64 & 0.22 \\
\hline 3 & 63 & 0.22 & 62 & 0.22 \\
\hline 4 & 61 & 0.22 & 69 & 0.20 \\
\hline 5 & 57 & 0.21 & 57 & 0.20 \\
\hline
\end{tabular}

TABLE 4: Stress utilization ratio for 5 most critical members in the wave direction of 30 degree

\begin{tabular}{|c|c|c|c|c|}
\hline Rank & \multicolumn{2}{|c|}{ Node I } & \multicolumn{2}{c|}{ Node J } \\
\hline & Element & $\begin{array}{c}\text { Stress } \\
\text { Utilisation }\end{array}$ & Element & $\begin{array}{c}\text { Stress } \\
\text { Utilisation }\end{array}$ \\
\hline 1 & 70 & 0.28 & 70 & 0.27 \\
\hline 2 & 69 & 0.24 & 69 & 0.23 \\
\hline 3 & 63 & 0.22 & 64 & 0.22 \\
\hline 4 & 61 & 0.22 & 62 & 0.22 \\
\hline 5 & 57 & 0.20 & 59 & 0.19 \\
\hline
\end{tabular}

TABLE 5: Highest stress utilization ratio of 5 structural members (wave direction of 45 degree)

\begin{tabular}{|c|c|c|c|c|}
\hline Rank & \multicolumn{2}{|c|}{ Node I } & \multicolumn{2}{c|}{ Node J } \\
\hline & Element & $\begin{array}{c}\text { Stress } \\
\text { Utilisation }\end{array}$ & Element & $\begin{array}{c}\text { Stress } \\
\text { Utilisation }\end{array}$ \\
\hline 1 & 70 & 0.25 & 70 & 0.25 \\
\hline 2 & 69 & 0.24 & 69 & 0.24 \\
\hline 3 & 63 & 0.19 & 64 & 0.22 \\
\hline 4 & 61 & 0.19 & 62 & 0.22 \\
\hline 5 & 59 & 0.18 & 59 & 0.20 \\
\hline
\end{tabular}

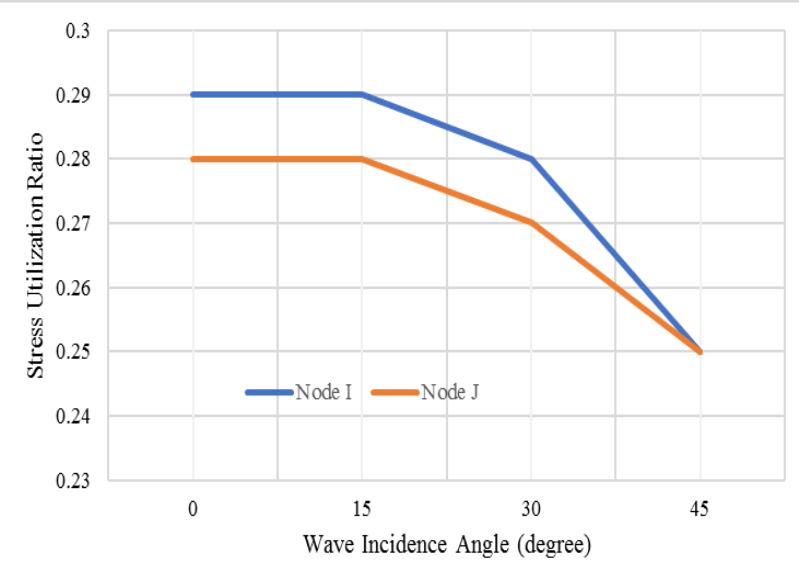

Fig. 5: Stress utilization ratio for critical element no. 70 versus wave incidence angle.

As a comparison to the results, an in-place analysis is carried out. In the in-place analysis, the only forces experienced by the structure due to its weight, i.e. due to gravity forces, as well as the buoyancy effect from the surrounding fluid are considered. The stress utilization ratio of the most critical member in place analysis is 0.2232 . There is a decrease of $28.3 \%$ of the stress utilization ratio compared to the structure where the environmental loadings are imposed. From here, the author concludes that the structure is sturdy as the environmental loading only contribution $28.3 \%$ to the overall stress experienced by the structure. The comparison for the in-place analysis and the analysis executed with environmental load is illustrated in Fig. 6.

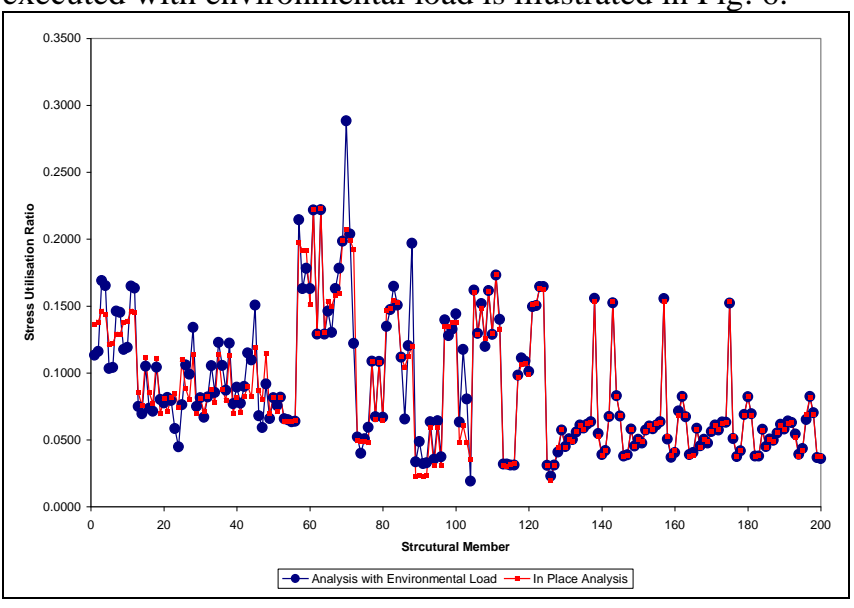

Fig. 6: Stress utilization ratio for the whole structure - In place analysis for wave direction of 0 -degree.

VII. CONCLUSSIONS

A procedure for probabilistic analysis in the solution of dynamic time-domain analysis of marine structure has been outlined. The response statistic generated indicates that the simulations generated in the time domain can predict the results of the studies with the coefficient of variation, $\mathrm{CoV}$ of $5 \%$.

Results obtained for the jacket platform, indicate that most of the critical members are situated at the second elevation from the mudline. The structural member that has the highest stress utilization ratio is element 70 which is an inclined member 
between elevations $21.8 \mathrm{~m}$ and $43.3 \mathrm{~m}$. It has a stress utilization ratio of 0.2884 . This low-stress utilization ratio meant that the level of reserve strength is high and able to support all loads that may be encountered by the structure. Therefore, it can be concluded that the structure is robust.

\section{REFERENCES}

[1] Madsen M.N., Nielsen J.B., Klinting P. and Knudsen J. (1988). A Design Load Method For Offshore Structures Based Upon the Joint Probability of Environmental Parameters. $7^{\text {th }}$ International Conference on Offshore Mechanics and Arctic Engineering. February 7-12, 1988. USA: ASME, 75-80.

[2] Bitner-Gregersen E.M. and Haver S. (1991). Joint Environmental Model for Reliability Calculations. Proceedings of the $1^{\text {st }}$ Int. Offshore and Polar Engineering Conf. $11^{\text {th }}-16^{\text {th }}$ August 1991. UK: ISOPE. 246-253.

[3] Kolios, A., Jusoh, I. and Brennan, F.P. (2009), "Sensitivity analysis of partial safety factors to the design of offshore steel structures", Proceedings of the 7th International Probabilistic Workshop, The Netherlands, 24 - 25 November 2009

[4] Jusoh, I., Okada, H., and Liu, H., (2000); Application of Probabilistic Method in Assessing the Reliability of Offshore Jacket Structure. Jurnal Teknologi, Universiti Teknologi Malaysia. Dec. 2000.
[5] Hagemeijer P.M. (1989). A Comparison between a Deterministic an Probabilistic Fluid Loading Model for a Jacket Structure. $8^{\text {th }}$ International Conference on Offshore Mechanics and Arctic Engineering. March 19-23 1989. The Hague: OMAE. 89-97.

[6] Wheeler J.D. (1970). Methods for calculating Forces Produced by Irregular Waves. Journal of Petroleum Technology. 359-367.

[7] Gusmestad O.T. and Karunakaran D. (1990). Wave Current Interaction. In: Environmental Forces on Offshore Structures and their Prediction Vol. 26. London: Society for Underwater Technology. 81-110.

[8] Torhaug R. (1996). Extreme Response of Nonlinear Ocean Structures: Identification of Minimal Stochastic Wave Input for Time-Domain Simulation. PhD Thesis, Stanford University.

[9] Winterstein S.R. and Torhaug R. (1993). Estimating Extreme Response of Jackup Structures from Limited Time-Domain Simulation. $12^{\text {th }}$ International Conference on Offshore Mechanics and Arctic Engineering. United States of America: ASME, 251-258

[10] API RP2A WSD (America Petroleum Institute). (2010). Recommended Practice for Planning, Designing and Constructing Fixed Offshore Platforms-Working Stress Design. Washington D.C. 